\title{
Dos nuevos cuadros de Alonso Vázquez y la influencia de Maerten de Vos en su obra
}

\author{
Two new paintings of Alonso Vázquez and the influence of \\ Maerten de Vos in his production
}

\section{Elena Escuredo Barrado ${ }^{1}$ \\ Universidad de Sevilla}

\begin{abstract}
Resumen: Gracias al hallazgo de dos nuevas tablas se amplía el catálogo de Alonso Vázquez, pintor destacado en la Sevilla finisecular. El estudio en profundidad y el análisis comparativo ofrece aportes significativos y permite establecer relaciones con otras pinturas conservadas del artista, al tiempo que se determina la influencia que tuvo el flamenco Maerten de Vos en sus composiciones, tanto en obras sevillanas como en su etapa final, la cual se desarrolló en México a partir de 1603.
\end{abstract}

Palabras clave: Alonso Vázquez, Sevilla, Pintura española, siglo XVI, Bautismo de Cristo, San Ildefonso, Maerten de Vos, estampas.

Abstract: Two new paintings are attributed here to the Seville painter Alonso Vázquez, attending to the style and composition. This analysis allows to establish the relationship of these new works with other preserved paintings of the artist, enlarging his production and showing the influence that the Flemish painter Maerten de Vos had in his compositions. Specially in the Vázquez Sevillian production, at his final stage, before he leaved Seville and settled in Mexico in 1603.

Key Words: Alonso Vázquez, Seville, Spanish Painting, $16^{\text {th }}$ century, Baptism of Christ, St. Ildefonso, Maerten de Vos, engraving.

1 (ii) https://orcid.org/0000-0001-7976-8925

(C) 2019 Philostrato. Revista de Historia y Arte 


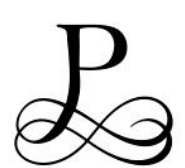

rocedentes del coleccionismo privado, llegaron al mercado de arte dos tablas de formato estrecho y alargado, en un excelente estado de conservación: un Bautismo de Cristo y una Imposición de la Casulla a San Ildefonso. (Figs. 1 y 2) Se trataban de dos primorosas obras del pintor Alonso Vázquez. Aunque apenas llegan a los sesenta centímetros de altura, por unos veinte de ancho, la calidad no entiende de medidas. El estudio detenido de las mismas y los datos aportados por los intermediarios me permitieron sostener y afirmar su autoría ${ }^{2}$. Ignoro su paradero actual, aún así, el antiguo propietario tuvo la amabilidad de cederme unas imágenes para su estudio, a fin de elaborar el presente artículo, dándolas así a conocer por primera vez.

Alonso Vázquez fue uno de los pintores más destacados de la ciudad de Sevilla a finales del siglo $\mathrm{XVI}^{3}$. De orígenes humildes, debió nacer en la ciudad bética, a tenor de lo expresado en su testamento ${ }^{4}$. Pacheco lo presentó como un excelente pintor de sargas, especialidad menor desde la que evolucionó para imponerse como estimado pintor al óleo e, incluso, ducho autor de frescos, situándolo en línea con Luis de Vargas, César Arbasía o Mateo Pérez de Alesio ${ }^{5}$. Puesto que el panorama pictórico sevillano había quedado huérfano de referentes desde la muerte de Luis de Vargas, acontecida en 1567, su buen quehacer fue pronto admirado y deseado. A este pintor "de buen gusto" y "figuras esbeltas y airosas"6, se le sucedieron los encargos, lo cual le permitió alcanzar cierta solvencia económica y erigirse como una de las máximas figuras pictóricas de la urbe junto al influyente Francisco Pacheco.

La primera obra de la que se tiene constancia del pintor data de 1590. Participó de forma activa en la renovación del monasterio de Santa Paula, asumió encargos tanto de órdenes religiosas como de particulares y trabajó para diversos lugares del Antiguo Reino de Sevilla como Marchena o Lepe. A pesar de que han sido muchos los diversos contratos notariales localizados

\footnotetext{
${ }^{2}$ Las características de las tablas son: Bautismo de Cristo (o./t., $59.9 \times 20 \mathrm{~cm}$ ); Imposición de la casulla a San Ildefonso $(0 . / \mathrm{t}$., $59.6 \times 19.8 \mathrm{~cm})$. Las medidas incluyen la extensión de 2 centímetros en la parte superior de ambas tablas. Agradezco enormemente las facilidades y la amabilidad de Don Manuel Gil Salas al enviarme las imágenes para su estudio y futura publicación.

${ }^{3}$ Su fama queda corroborada en el último estudio relacionado con su vida y obra, donde se detalla el enfrentamiento que sostuvo con otros pintores de la ciudad cuando se negó a compartir la realización de un ciclo de pinturas. Jesús Palomero Páramo, "Los pintores sevillanos contra Alonso Vázquez por negarse a repartir los frescos del convento de San Francisco: injurias, amenazas y atentados. iA las armas!", en Las ruinas. Concepto, tratamiento y conservación, María del Valle Gómez de Terreros Guardiola y Luis Pérez-Prat Durbán (eds.), (Universidad de Huelva, Huelva, 2019), pp. 299-242.

${ }^{4}$ A pesar de que la historiografía había situado su nacimiento en Ronda o Antequera, el hallazgo de su testamento parece contradecir las fuentes, aunque a la espera de nuevos hallazgos documentales, el dato ha de ser tomado con cautela. Jesús Palomero Páramo, "Las últimas voluntades y el inventario de bienes del pintor Alonso Vázquez", Anales del Instituto de Investigaciones Estéticas, no 86, (2005), p. 171.

${ }^{5}$ Francisco Pacheco, Arte de la Pintura, libro III, (Sevilla: Impresor Simón Fajardo, 1649) p. 344.

${ }^{6}$ Antonio Palomino, Museo pictórico y escala óptica, (Madrid: Aguilar, ed. 1947), p. 868.
} 
en los vastos fondos del Archivo de Protocolos de Sevilla, por desgracia, ninguno se corresponde con las tablas que aquí se presentan?

Este Bautismo de Cristo e Imposición de la Casulla a San Ildefonso proceden de la jerezana Colección Marqués de Domecq. Aunque este maestro ya había cultivado la primera iconografía con anterioridad ${ }^{8}$, en una obra conservada en la catedral de Sevilla, el segundo motivo es novedoso en su producción. El análisis estilístico de las mismas invita a situarlas al final de su etapa sevillana, antes de embarcar a México, hacia donde partió en 1603 y de donde no regresará jamás ${ }^{9}$. A pesar de que son composiciones poco complejas, Vázquez no adolece de la rigidez que muestran algunas de sus primeras obras y las figuras ganan en dulzura, algo que se hace especialmente patente en el rostro de María. La suavidad en los gestos, la elegancia de las formas y esa "enfática gesticulación de filiación manierista"10, permiten situar estos trabajos entre 1600 y su partida hacia el nuevo continente, pues comparte los grisáceos y nebulosos cielos de San Pedro Nolasco despidiéndose de Jaime I (1600) del museo de Bellas Artes de Sevilla (inv. no CE 0106P) y los tipos físicos y valores cromáticos de El tránsito de San Hermenegildo (1603) del mismo museo (inv. n D00138P), obra de la que sólo realiza la parte terrenal, siendo Juan de Uceda el encargado de realizar la zona gloriosa superior.

En ambas tablas del Bautismo y la Imposición precede al medio punto que las cierra unas entradas a derecha e izquierda que son indicativas del soporte que las cobijó. Debían estar engastadas en un retablo de columnas o pilastras, siendo el perfil de los capiteles lo que se recorta sobre las nubes y junto a las cabezas de los querubines. Sea como fuere, hemos de imaginarlas flanqueando una tabla central de mayores proporciones, conforme a lo acostumbrado. A la espera de nuevos hallazgos tanto documentales como pictóricos, es imposible realizar conjeturas sobre la temática que debía presidir el altar para el que fue concebido.

Mientras que el tema del Bautismo de Cristo disfruta de una amplia tradición, la iconografía de la Imposición se hizo especialmente querida y demandada tras el Concilio de Trento ${ }^{11}$. Frente a las ideas luteranas que

\footnotetext{
7 Celestino López Martínez, Desde Martínez Montañés hasta Pedro Roldán, (Sevilla: Tipografía Rodríguez Giménez y compañía, 1932) pp. 206-218.

${ }^{8}$ Enrique Valdivieso, Historia de la pintura sevillana, (Sevilla: Guadalquivir S. L., 1992), p. 92.

${ }^{9}$ Vázquez pasó a México formando parte del séquito de Juan de Mendoza y Luna, Marqués de Montes Claros, quien fue sucesivamente el undécimo Virrey de Nueva España (1603-1607) y del Perú (16071615). Vázquez fue considerado el mejor pintor del momento en Sevilla y no pudiendo renunciar a la propuesta del conocido como "virrey poeta", dejó obras incompletas en la capital del Guadalquivir para embarcarse en la aventura americana. José Rogelio Ruiz Gomar Campos, "El paso de Alonso Vázquez a Nueva España", en Andalucía y América en el Siglo XVII: actas de las III Jornadas de Andalucía y América, vol. 2, Bibiano Torres Ramírez y José J. Hernández Palomo (coord.), (La Rábida: Universidad de Santa María de la Rábida, 1985), pp. 163-170.

10 Benito Navarrete Prieto, "Precisiones y adiciones al catálogo de Alonso Vázquez y Francisco Pacheco", Archivo hispalense: Revista histórica, literaria y artística, no 328, tomo 78, (1995), p. 153.

"Juan Carmona Muela, Iconografía de los santos, (Madrid: Akal, 2009), p. 203.
} 

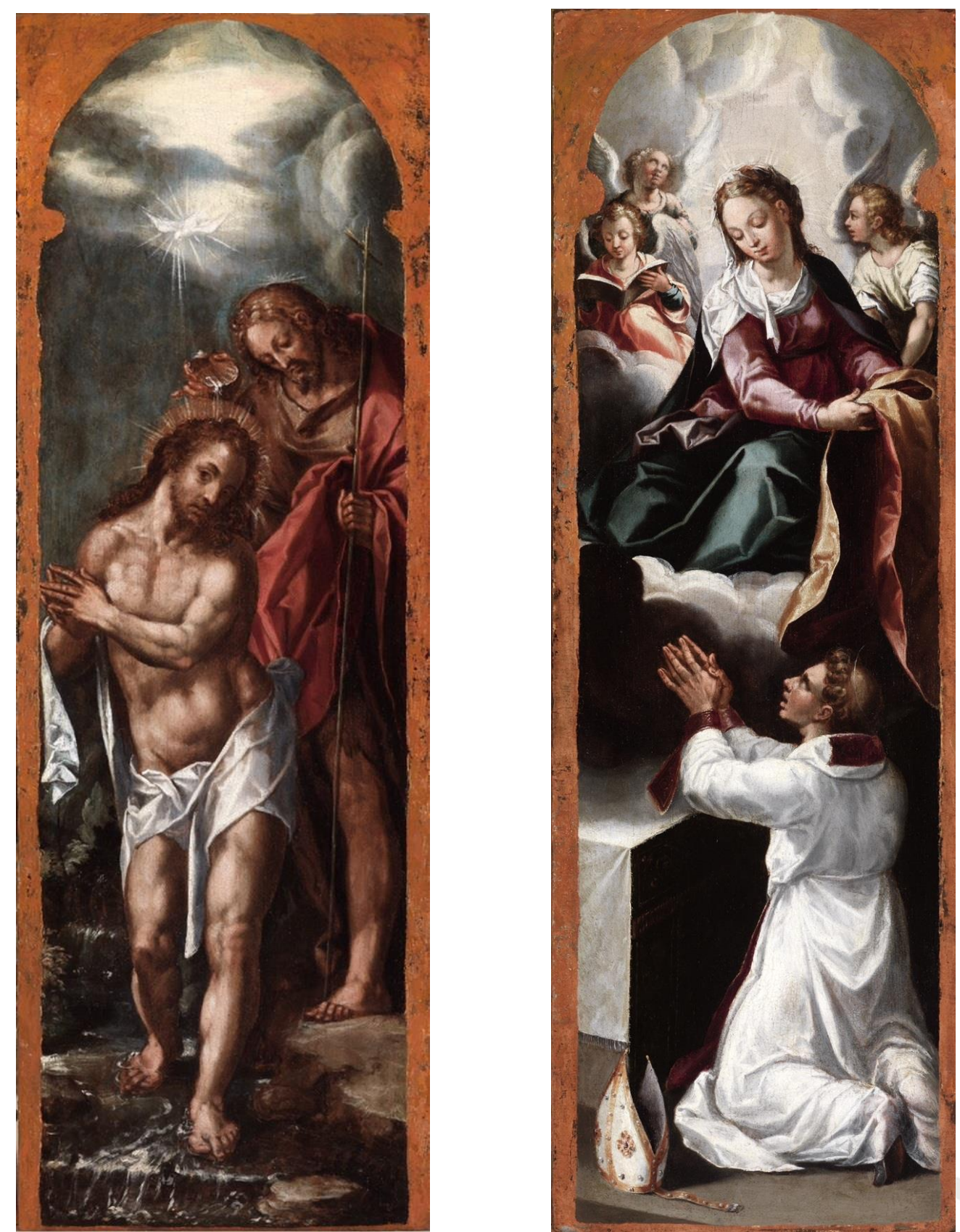

Fig. 1 y Fig. 2. Alonso Vázquez, Bautismo de Cristo y la Imposición de la casulla a San Ildefonso. ca. 1600-1603.

Paradero desconocido.

desprestigiaron la figura de María, negando incluso su culto como mediadora e intercesora, la Iglesia Católica contrarrestó la situación realizando una férrea defensa, de manera que la imagen, tanto espiritual como iconográfica, de la Madre de Dios salió ampliamente reforzada. Este hecho conllevó una leve, aunque importantísima modificación en la plasmación de esta escena de la vida del Santo. Si anteriormente se había 
mostrado a la Virgen sedente en un trono, ahora un lecho de nubes haría las veces de sitial, situándola así en un plano más elevado, celeste y glorioso ${ }^{12}$. El tema se convirtió en un paradigma tridentino que tomó a San Ildefonso como figura referencial por haber sido un obispo que defendió acérrimamente el papel de María como intercesora en la lucha contra los herejes e infieles. La revalorización de su figura tras el Concilio estuvo más que justificada. Asimismo, el extendido culto al santo toledano confirmaba la tradición, otro de los pilares especialmente atacados por Lutero. En San Ildefonso, la tradición encontraba un respaldo tácito y un modelo indubitable, pues existía constancia de su vida y de sus obras gracias a los escritos y reliquias que se conservaban todavía ${ }^{13}$ :

"Por la tradición tenemos muchas cosas a fé... Está acreditada por el santo Concilio de Trento: y es un grande argumento para conuencer a algunos de los hereges, particularmente de los antiguos, como consta en Tertulliano porque negando las escrituras, no se atreuian a la tradición"14

No obstante, aunque su imagen se difundió notablemente durante el siglo XVII, Vázquez contó con un referente iconográfico de excepción, realizado por Pedro de Campaña en 1555. (Fig. 3) Se trata de una de las tablas laterales que integran el Retablo de la Purificación, más conocido como del Mariscal, en la capilla homónima de la Magna hispalense, el cual fue ejecutado por encargo del señor don Diego Caballero, cuyo cargo da nombre al conjunto ${ }^{15}$. Sin duda, Vázquez empleó esta tabla como guía fundamental, a tenor del esquema compositivo, la posición arrodillada del santo con la mitra en el escabel o la mesa de altar sobre la que descansa el sitial nebuloso que porta a la Virgen. Aunque el santo gana en juventud en la obra de Vázquez, en ambas obras aparece con el tradicional hábito blanco, siendo la casulla de un sobrio dorado, sin estridencias. Además, un detalle certero con el que se respalda la atribución y la cronología propuesta deriva del análisis detenido de la mitra, la cual es idéntica a la que corona la figura del San Blas, tabla central del primer cuerpo del retablo mayor que pintó para el Hospital de las Cinco Llagas, datado en $1603^{16}$.

Aparte de referenciar gráficamente a Campaña, es muy probable que Vázquez buscara inspiración en alguna estampa para realizar la figura de

12 Emile Mâle, L'art religieux de la fin du XVIe, siécle du XVIIe. siécle et du XVIII siécle, (París: Armand Collin, 1951), p. 194.

13 Rosa López Torrijos, "Iconografía de San Ildefonso desde Sus orígenes hasta el siglo XVIII", Cuadernos de Arte e Iconografía, tomo 51, no 204, (1978), pp. 430-437.

14 Pedro Salazar De Mendoza, El Glorioso Doctor San Ildefonso, Arçobispo de Toledo. Primado de las Españas, (Toledo: Diego Rodríguez impresor, 1618), p. 76.

${ }^{15}$ Enrique Valdivieso, Pedro de Campaña, (Sevilla: Fundación Endesa, 2008), pp. 102-II 2.

${ }^{16}$ En la actualidad, este excepcional retablo se encuentra cegado por un gran lienzo que oculta la que fue la cabecera de la iglesia del dicho Hospital, la cual ha sido convertida en Salón de Plenos del Parlamento de Andalucía. Sobre el retablo, véase: Juan Miguel Serrera Contreras, "Alonso Vázquez: el retablo mayor del Hospital de las Cinco Llagas", Archivo hispalense: Revista histórica, literaria y artística, 74, no 227 (1991), pp. 139-184. 


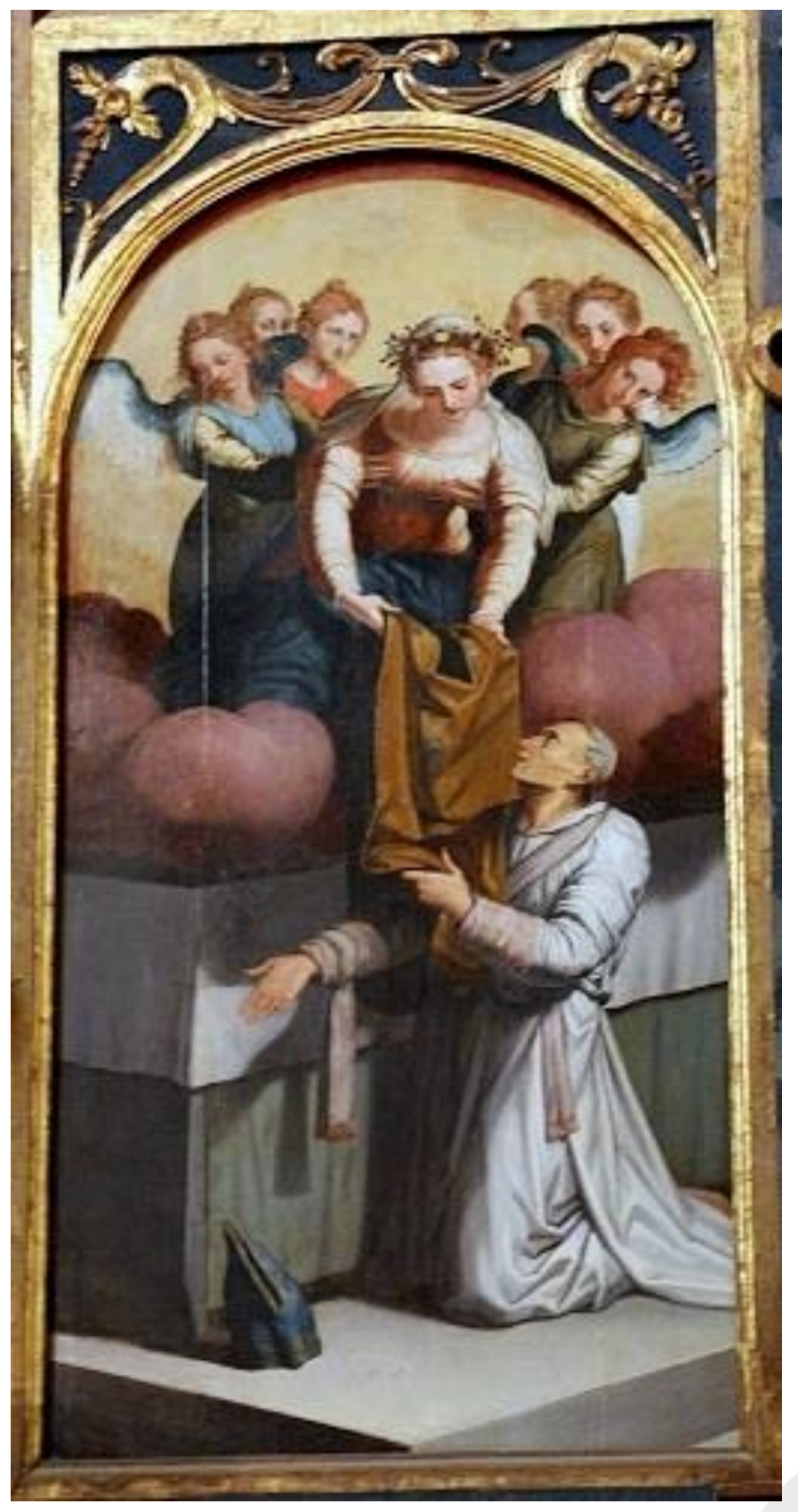

Fig. 3. Pedro de Campaña, Imposición de la casulla a San Ildefonso. 1555. Retablo del Mariscal, Sevilla, Catedral (Foto autor@)

María, de una belleza dulce y exquisita, quizá de las más elegantes de cuantas se le conocen. De rostro aniñado, entorna los párpados para mirar al santo, al que dedica una tierna y sutil sonrisa. Hubo de poseer una nutrida colección de estampas donde abundarían las composiciones de 
grandes artistas nórdicos, como Durero o Martin de $\operatorname{Vos}^{17}$. De este último, es posible que contara con la serie "San Pablo y escenas de la vida de Cristo", pues uno de estos grabados fue fundamental para componer, en 1590, el registro inferior de su Resucitado de la Iglesia de Santa Ana, de Triana -sobre el que luego volveremos ${ }^{18}$. En la Adoración de los Magos, de esa misma serie de estampas aparece una Virgen que bien pudiera haber guiado sus trazos para crear aquella que impone la casulla a San Ildefonso. Aunque modifica la figura para adaptarla a las exigencias compositivas, el modelo virginal comparte el paradigma estético de la tablita en venta. Una mujer recatada, de belleza juvenil, gran finura y pulcra elegancia se aparece a un santo que eleva su mirada y une sus manos en señal de agradecimiento y oración.

El Bautismo de Cristo, por su parte, muestra un dibujo preciso, esencial en el cultivo de una poderosa anatomía que otorga vigor a las formas, mientras la expresión transita entre la severidad y la solemnidad. El sutil torrente de agua del Jordán, que fluye bajo los pies de Cristo, crea reflejos lechosos que entroncan con la radiante gloria del Espíritu Santo, en un inteligente juego de blancos con que el pintor equilibra la escena, enredando la luz en los quebrados pliegues de la túnica de Jesús. Aunque la composición no resulta una copia fidedigna de ninguna estampa, recuerda a aquella grabada por Cornelis Cort en 1575 tanto en la postura de Cristo, como en la tipología del paño y caída de la túnica sobre el brazo izquierdo (Fig. 4).

Los colores son muy característicos de la producción de Vázquez, en especial el blanco con sombras grisáceas, con el cual realiza un extraordinario estudio de texturas, pues los angulosos plisados de tela se acartonan entrono a la cintura de Cristo, mientras que la suavidad ondulante en la toca de María o el hábito del santo, denotan una telas menos pesadas y más mórbidas. Junto a él no podía faltar su color carmín de Florencia, tan apreciado por Pacheco:

"Yo he hecho con este color algunos terciopelos bien imitados, pero todos quedan atrás con los de mi compañero Alonzo Vázquez, que ninguno le igualó en esta parte"19.

\footnotetext{
17 En el inventario post-morten de sus bienes se recogen "papeles de mi arte y modelos", los cuales deben interpretarse como los grabados existentes en su haber fundamentales para la tarea compositiva. Jesús Palomero Páramo, "Últimas voluntades...", p. 178.

18 La serie Evangelicae Doctrinae se compone de seis grabados, con diseños de Maerten de Vos y grabados por Jan Sadeler: San Pablo en un nicho, La adoración de los pastores, El Bautismo de Cristo, Cristo en la cruz, la Resurrección y Cristo niño bendiciendo. De esta última obra existe un dibujo en Windsor Castel, fechado en 1582 (Colección de S.M la Reina Isabel II, no inv. 12961). Christiaan Schuckman, (comp.) y D. De Hood Scheffer (ed.), Hollstein's Duch \& Flemish etchings, engravings and woodcuts 1450-1700, vol. XLIV, (Rotterdam: Sound \& Vision Interactive, 1996), pp. 95-96; Christiaan Schuckman, (comp.) y D. De Hood Scheffer (ed.), Hollstein's, vol. XLV, part I, pp. 152-153; Isabel De Ramaix y Miriam West (ed.), The Illustrated Bartsch. Jan Sadeler I, vol. 70, part 1, (Londres: Abaris Book, 2012), pp. 134-141.

${ }^{19}$ Francisco Pacheco, Arte de la pintura, libro III, p. 390.
} 


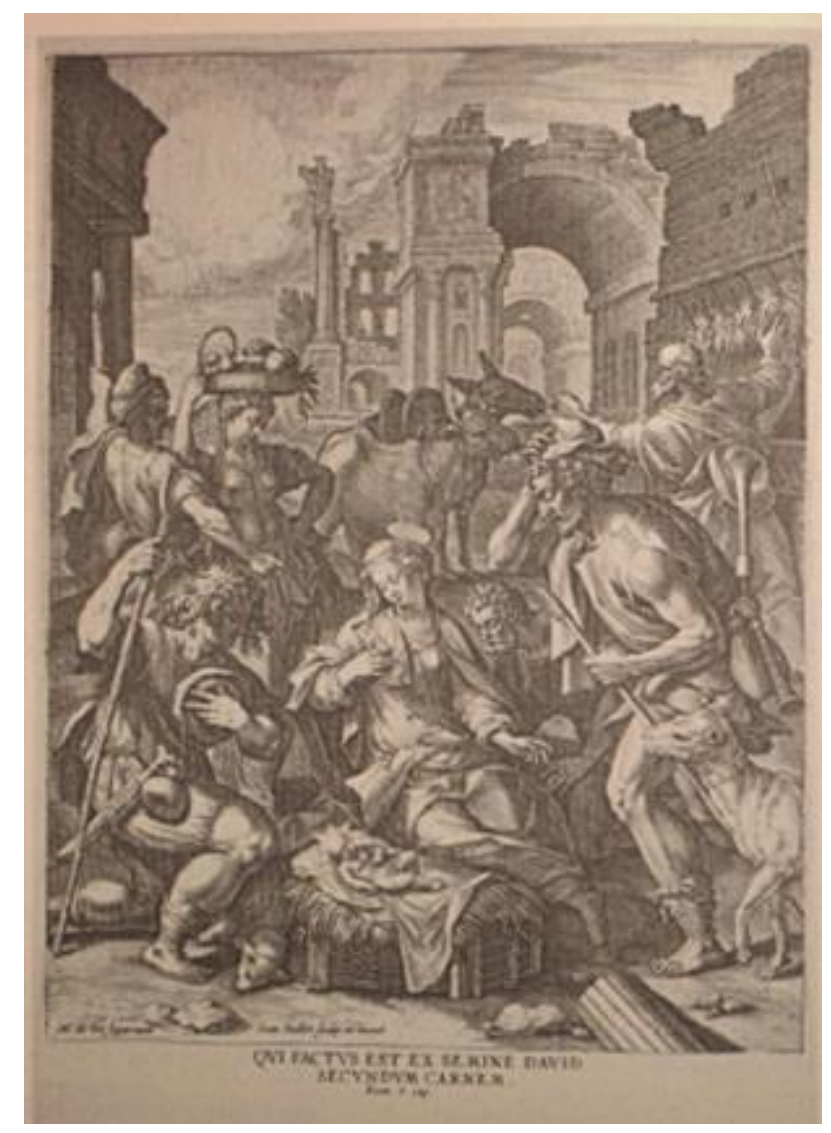

Fig. 4. Jan Sadeler siguiendo a Maerten de Vos Adoración de los Magos. Grabado, serie de San Pablo y escenas de la vida de Cristo

No es la única vez que Pacheco alaba la obra de Vázquez, con quien trabajó para satisfacer el encargo de la Orden Mercedaria. En ambos recayó la responsabilidad de realizar un ciclo, integrado por grandes lienzos, donde se narraran diversos episodios de la vida de San Pedro Nolasco y San Ramón Nonato, ilustres hermanos de la orden, destinados a decorar el claustro grande de su sede sevillana ${ }^{20}$. Entre las diversas menciones que Pacheco le dedica en sus escritos, cabe destacar aquella en la que ensalzó su capacidad para cultivar los lejos, es decir, el paisaje. Este comentario fue puesto en relación con excepcional verdor con que había realizado la Aparición del Ángel a los pastores, un lienzo que el artista pintó para el convento trinitario de la capital hispalense ${ }^{21}$. Por aquel entonces, el paisaje no se había constituido aún como género, tan solo era un complemento necesario en algunas escenas de exterior, como en décadas anteriores lo

\footnotetext{
${ }^{20}$ Informa del encargo el propio Pacheco, Arte de la pintura, tomo II, p. 14. Sobre la serie de cuadros, ver el análisis de José Fernández López: Programas iconográficos de la pintura barroca sevillana, (Sevilla: Universidad de Sevilla, 2002) pp. 252-261. Actualmente, el antiguo convento de la Merced alberga el Museo de Bellas Artes de Sevilla.

${ }^{21}$ Pacheco, Arte de la pintura, libro III, p. 409
} 


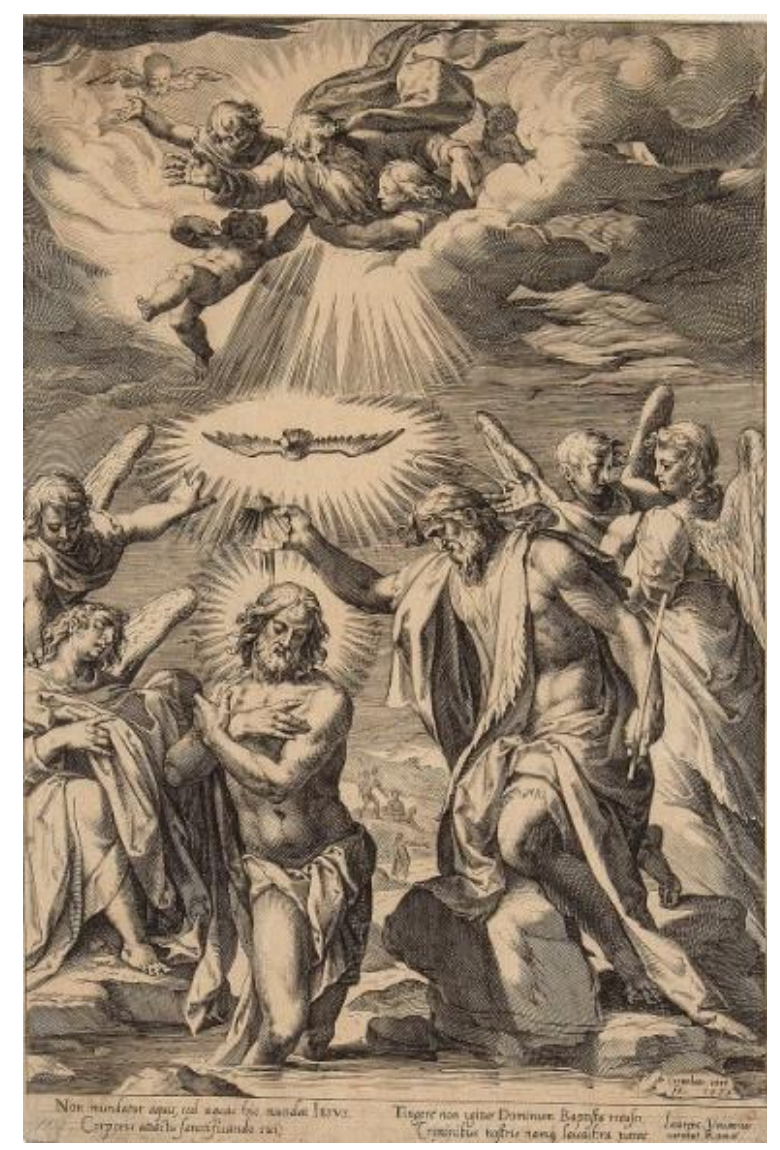

Fig. 5. Cornelis Cort siguiendo a Maerten de Vos, Bautismo de Cristo, 1578, grabado.

habían sido las ruinas ${ }^{22}$. Sin embargo, poco a poco los lejos van ganando en vegetación, en diversidad cromática y en protagonismo. Una de las razones que aducen esta progresiva proliferación de pinturas en la que se impone la primacía del verdor a la figuración, se debe buscar en el cambio de gusto y en las nuevas demandas. El mercado se copó de obras flamencas donde la quietud, el silencio y el bucolismo de frondosos árboles y coloridos arbustos ofrecía a las fortunas pudientes inmejorables decoraciones para sus aposentos. Este tipo de obras fue cultivado por el pintor durante su estancia mejicana, lo que aporta evidencias de la demanda que produjo su obra y de lo sagaz que fue para adaptarse a un mercado al alza. En poder del virrey poeta se contaban "veinte y ocho tarjas de lejos", cuya iconografía se desconoce ${ }^{23}$. Para realizar este tipo de lienzos, en los que -se junta la sierra con el cielo", en palabras de Pacheco, contó con unos modelos de excepción, pues se tiene constancia de que en el aposento que le fue

\footnotetext{
22 La importancia del paisaje de ruinas en el pleno Renacimiento fue bien analizada y estudiada por Nicole Dacos, «Roma quanta fuit». O la invención del paisaje en ruinas, (Barcelona: Acantilado, 2014).

23 Palomero Páramo, "Últimas voluntades...", p. 180.
} 
concedido en las Casas Reales (México), Vázquez poseía tres lienzos de paisajes de mano de Maerten de Vos.

No sólo este pintor flamenco fue referente fundamental de Vázquez ${ }^{24}$, también los grabados nórdicos le ofrecieron modelos muy precisos, y dado el seguimiento tan fidedigno que solía hacer de ellos, lo sitúan como un gran copista, a la vez que dejan en evidencia su capacidad creativa. El hecho de que abusara del empleo de estampas imprimió un carácter rígido a su obra, la cual, en ocasiones, adolece de cierto estatismo y falta de naturalidad, haciéndolo especialmente vulnerable en composiciones con muchos personajes. Para su cuadro de Cristo resucitado, de la trianera iglesia de Santa Ana, también en la capital hispalense, copia de forma exacta el soldado que duerme a los pies del sepulcro. Toma el modelo de la escena de la resurrección de la serie antes mencionada, San Pablo y escenas de la vida de Cristo. (Fig. 6) Es un calco literal, donde no modifica ni el extremo de la empuñadura de la espada ni la ornamentación del casco. Algo que no sucede en la figura de Cristo, la cual deriva de otra estampa, pero en este caso la copia no es mimética. El Cristo se dispone sobre el sepulcro, como es habitual, mientras algunos guardias duermen y otros se sobrecogen por lo prodigioso y repentino del acontecimiento que está teniendo lugar. En este caso, para la figura gloriosa toma como referencia otra composición de Maerten de Vos, llevada a la plancha por uno de los Wierix en una serie de La Pasión de Cristo, donde modifica levemente la posición del brazo izquierdo para que pueda portar una cruz triunfante, algo que tampoco aparece en el grabado ${ }^{25}$. A pesar de esa leve adaptación, su anatomía y el movimiento volado de la capa está tomado al milímetro, como si de un ejercicio de calco o "sacado de puntos" se tratara. Los querubines que revolotean sobre la cabeza del Redentor también aparecen en la estampa, aunque en mayor número que en la tabla. En este caso, frente a la dulzura de las obras aquí presentadas, esta pieza destaca por la monumentalidad de las figuras, con un certero estudio anatómico de poderosas musculaturas deudoras de las formas miguelangelescas que bien pudo haber aprendido Vos de primera mano de ser cierta su estancia en Italia ${ }^{26}$.

Junto a ella, debe estudiarse otra obra presente en Santa Ana y que debió formar parte de una estructura retablística que la integraba junto al Resucitado como pieza principal, y un San Martín partiendo la capa en el otro lateral. Se trata de un San Cristóbal, donde prevalecen los mismos valores estéticos, resultando su composición de otra invención de Maerten

${ }^{24}$ Sobre la influencia de Maerten de Vos en Sevilla en el siglo XVI: Diego Angulo Íñiguez, "Martin de Vos en España y Méjico", en Miscellanea prof. Dr. D. Roggen, (Amberes: De Sikkel, 1957), pp. 9-14.

${ }^{25}$ Christiaan Schuckman, (comp.) y D. De Hood Scheffer (ed.), Hollstein's, vol. XLIV, Text, pp. 98-100 y Christiaan Schuckman, (comp.) y D. De Hood Scheffer (ed.), Hollstein's, vol. XLV, Plates, part I, pp. 159-160.

${ }^{26}$ Se piensa que pudo haber realizado un viaje a la península italiana entre 1552 y 1555 , pero no existen evidencias documentales que lo puedan confirmar. Giovanna Sapori, Fiamminghi nel cantiere Italia, 1560-1600, (Nápoles: Electa, 2007), p. 27. 


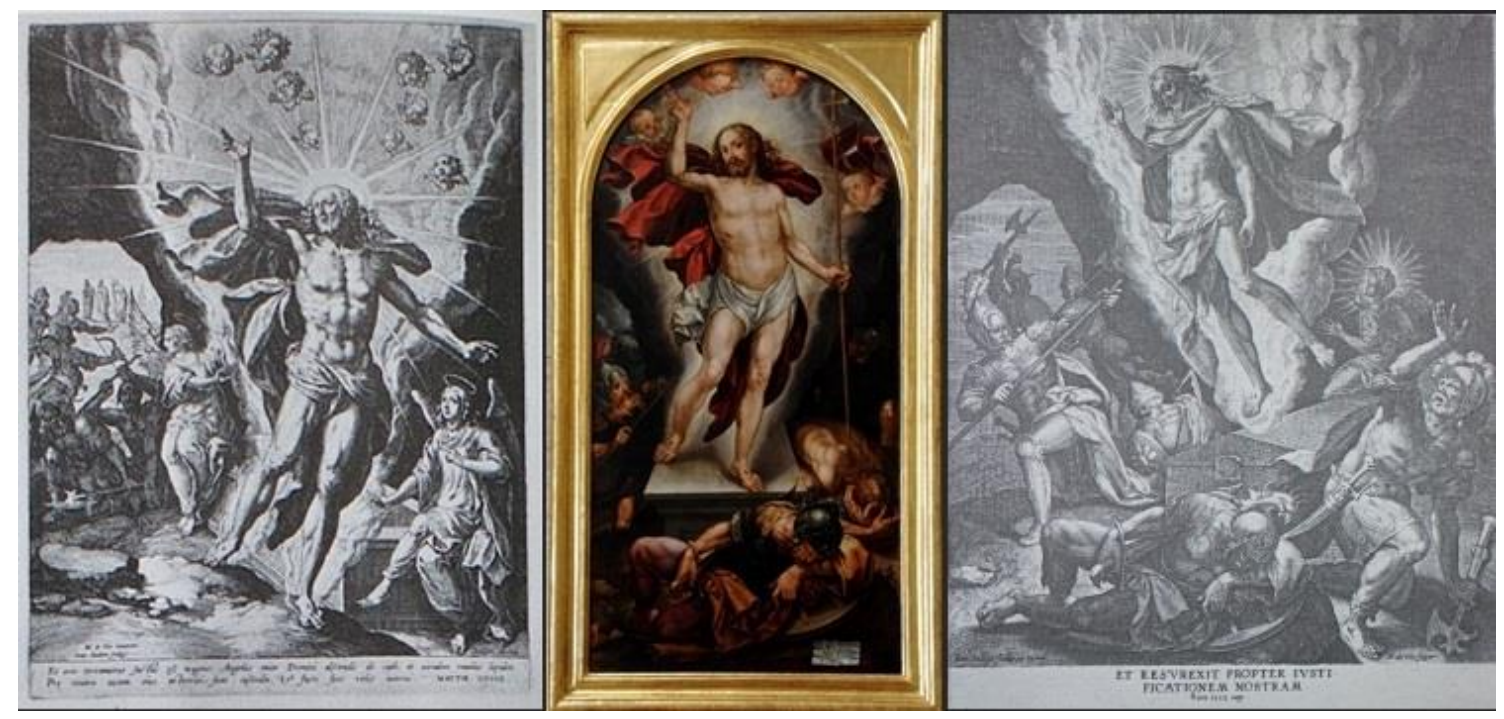

Fig. 6. Hermanos Wierix siguiendo a Maerten de Vos, Resurrección de Cristo. Grabado, perteneciente a la serie La Pasión de Cristo; Alonso Vázquez, Resurrección de Cristo, 1590. Sevilla, iglesia de Santa Ana (Foto autor@); Según Maerten de Vos, Resurrección de Cristo. Grabado de la serie San Pablo y escenas de la vida de Cristo.

de Vos, en este caso, llevada a la plancha por Antonius Wierix, el menor de los hermanos. (Fig. 7) El San Cristóbal es copia literal del grabado, donde ni los gestos ni los pliegues de la capa se dejan al azar o a la imaginación. Invierte la dirección de la composición, pero se complace en la imitación de la musculatura, las torsiones y el báculo con el que el santo intenta sostenerse en pie mientras porta la pesada carga del Niño. Llama la atención la presencia de un loro a los pies del gigante. No queda claro su significado, pero quizá sigue el ejemplo del gran fresco que Mateo Pérez de Alessio realizó en la Puerta del Príncipe de la Catedral de Sevilla en $1584^{27}$. Es un dato significativo que podría servir para establecer una datación aproximada de estas tres tablas, que no serían anteriores a esa fecha ni posteriores a 1600, dadas las diferencias estilísticas con las nuevas que aquí presentamos. El ave pintada por el italiano porta en su pico un papel en el que puede leerle el año y el nombre del autor. Se sitúa en un lugar secundario, siendo en apariencia, un mero detalle anecdótico. No obstante, podría aportar una lectura simbólica en doble grado. Por un lado, sería un guiño al exotismo de la tierra conquistada, a esa Sevilla receptora de objetos suntuosos, de originales colores y lujosas texturas, de animales nunca antes vistos y de plantas jamás imaginadas. Pero por otro, también puede ofrecer una lectura en clave cristiana, como una apología de la fe verdadera. La inteligente estrategia de apropiación cultural para sus propios

27 También con él entraron en Sevilla los modelos de Miguel Ángel, a quien sirvió, siendo casi anciano, moliendo colores en su taller. Nicoletta Lepri, "Matteo da Leccia e Vasari", Bolletino d'informazione / Brigata Aretina degli Amici dei Monumenti, no 34, (2000), pp. 21-29. 


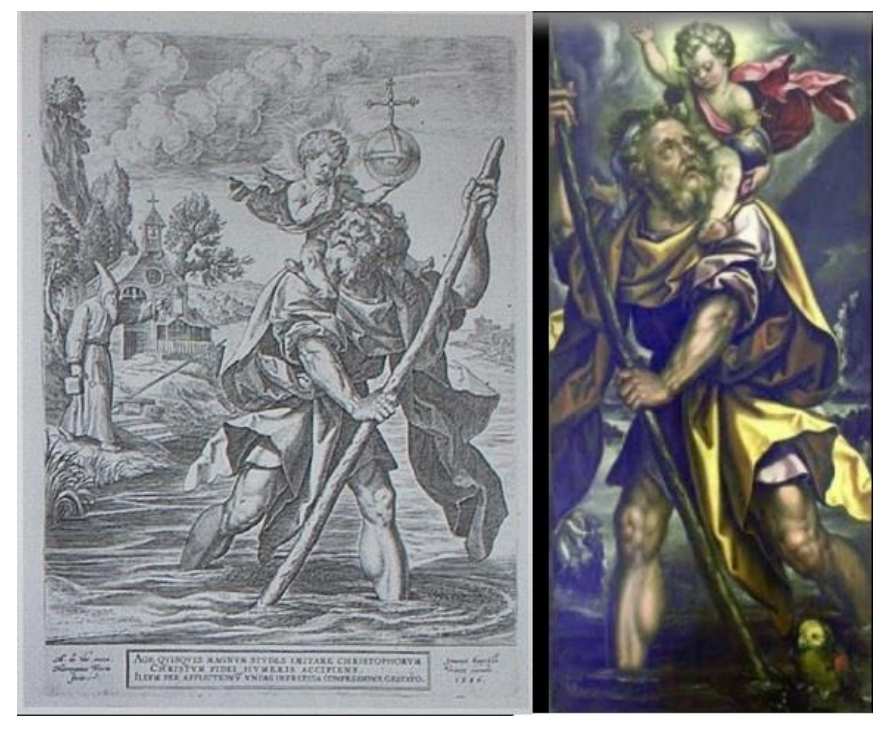

Fig. 7. Christian I de Passe siguiendo a Maerten de Vos, San Cristóbal. Grabado; Alfonso Vázquez, San Cristóbal, 1590. Sevilla, iglesia de Santa Anta (Foto autor@)

fines evangélicos y pastorales, que desde los primeros momentos demostró la iglesia, también tuvo su resonancia al otro lado del Atlántico. Los préstamos serán recíprocos, y las imágenes y los significados se convirtieron en mercancías de ida y vuelta. Los loros, pericos o guacamayos representaban diversas fuerzas divinas para los pueblos de Mesoamérica. Eran seres sagrados que anunciaban al Sol, siendo una epifanía del astro divino ${ }^{28}$. Por tanto, cristianizando el concepto antiguo, el loro, en su calidad de ser alado, como los ángeles mensajeros, sería el ave que anunciaría la llegada del Mesías, aquel que porta San Cristóbal sobre sus hombros.

Finalmente, cabe señalar que, además de contribuir a la ampliación del catálogo de Vázquez, las relaciones descritas y los análisis realizados no hacen más que verter nuevas reflexiones sobre la figura de Maerten de Vos en Sevilla y en América. Fue un artista transcontinental y transoceánico, uno de las más influyentes de su generación. Un pintor que, desde su lejana Amberes, se benefició del comercio con el Nuevo Mundo, gracias a la mediación mercantil de Sevilla. Hasta la capital hispalense llegaban libros, estampas y lienzos cuyo destino sería embarcar hacia América. Resulta muy singular que un artista registrado como "luterano" en el momento más crispado de las revueltas en las provincias del norte, en los años setenta y ochenta del siglo XVI, tuviera un éxito tan abrumador en la España contrarreformista de Felipe $\mathrm{II}^{29}$. De Vos fue un artista con una

28 Mercedes de la Garza: "Simbolismo de los loros en el mundo indígena mesoamericano", Revista de la Universidad de México, no 595, (2002) pp. 3-9.

${ }^{29}$ El propio monarca poseyó obras de Martin de Vos, según describe Gian Paolo Lomazzo, en 1590: 
extraordinaria visión comercial, pues trabajó para patrones de la nueva fe al tiempo que realizaba dibujos para estampas basadas en devociones católicas tradicionales. De esa forma se aseguró clientela en ambos bandos, viéndose su expansión favorecida por los vínculos familiares existentes en la villa francesa de Valenciennes, la cual se encontraba en la ruta hacia Rouen y Paris, dos de los centros principales para la exportación de mercancías hacia España cuando los puertos del norte estaban cerrados a causa de las revueltas ${ }^{30}$.

Si Maerten de Vos fue un referente en sí mismo, gracias a la existencia de obras suyas en América, enviadas vía Sevilla, a la circulación de sus invenciones grabadas y a la presencia de un compatriota como Simon Pereins, estas evidencias sobre la obra de Alonso Vázquez no hacen más que añadir otro ingrediente a ese idilio de "formas viajeras" que unió al inventor flamenco con los nuevos pintores novohispanos. Vázquez fue un vehículo más para el conocimiento de las creaciones de Maerten de Vos, siempre bajo el sevillano tamiz de su pintura, siendo su obra testigo de cómo los conceptos de "centro" y "periferia", tan en boga en la actualidad, desdibujaron sus perfiles en un perfecto galimatías artístico.

"E il gran Martin de Vos parimenti di Anversa pittore [...] Il quale oltre moltre altre opere portate que e là per il mondo a diversi Principi ne ha mandato quattro al Cattolico Filippo Re di Spagna, uno di Cristo all'Orto coi Discepoli [...] altro dell'Angelo con Lotto, e le figlie che fuggono dalle arse Città, il terzo di Santa Maria con figlio, con San Giuseppe [...] e I'ultimo d'una venere ignuda". Gianpaolo Lomazzo, Idea del tempio della pittura, (Milano, Paolo Gottardo Pronto, 1590), p. 162.

30 Stephanie Porras, "Trading with the enemy: The Spanish market for Antwerp prints and paintings during the Revolt", en Netherlandish art and luxury goods in Renaissance Spain, Daan Van Heesch, Robrecht Janssen y Jan Van der Stock (eds.), (Nueva York: Harvey Miller Publisher, 2018), pp. 93-106. 
Bibliografía:

Angulo Íñiguez 1957: Diego Angulo Íñiguez, "Martin de Vos en España y Méjico", en Miscellanea prof. Dr. D. Roggen, (Amberes: De Sikkel, 1957), pp. 9-14.

Carmona Muela 2009: Juan Carmona Muela, Iconografía de los santos, (Madrid: Akal, 2009).

Dacos 2014: Nicole Dacos, «Roma quanta fuit». O la invención del paisaje en ruinas, (Barcelona: Acantilado, 2014).

De la Garza 2002: Mercedes de la Garza: "Simbolismo de los loros en el mundo indígena mesoamericano", Revista de la Universidad de México, no 595, (2002) pp. 3-9.

De Ramaix y West 2012: Isabel De Ramaix y Miriam West (ed.), The Illustrated Bartsch. Jan Sadeler I, vol. 70, part 1, (Londres: Abaris Book, 2012).

Fernández López 2002: José Fernández López: Programas iconográficos de la pintura barroca sevillana, (Sevilla: Universidad de Sevilla, 2002)

Lepri 2000: Nicoletta Lepri, "Matteo da Leccia e Vasari", Bolletino d'informazione / Brigata Aretina degli Amici dei Monumenti, no 34, (2000), pp. 21-29.

Lomazzo 1590: Gianpaolo Lomazzo, Idea del tempio della pittura, (Milano: Paolo Gottardo Pronto, 1590).

López Torrijos 1978: Rosa López Torrijos, "Iconografía de San Ildefonso desde Sus orígenes hasta el siglo XVIII", Cuadernos de Arte e Iconografía, tomo 51, no 204, (1978), pp. 430-437.

Mâle 1951: Emile Mâle, L'art religieux de la fin du XVIe, siécle du XVIIe. siécle et du XVIII siécle, (París: Armand Collin, 1951).

Navarrete 1995: Benito Navarrete Prieto, "Precisiones y adiciones al catálogo de Alonso Vázquez y Francisco Pacheco", Archivo hispalense: Revista histórica, literaria y artística, no 328, tomo 78, (1995), pp. 149162.

Pacheco 1649: Francisco Pacheco, Arte de la Pintura, (Sevilla: Impresor Simón Fajardo, 1649).

Palomino 1715-1724: Antonio Palomino, Museo pictórico y escala óptica, (Madrid: Aguilar, ed. 1947).

Palomero Páramo 2005: Jesús Palomero Páramo, "Las últimas voluntades y el inventario de bienes del pintor Alonso Vázquez", Anales del Instituto de Investigaciones Estéticas, no 86, (2005), pp. 169-202. 
Palomero Páramo 2019: Jesús Palomero Páramo, "Los pintores sevillanos contra Alonso Vázquez por negarse a repartir los frescos del convento de San Francisco: injurias, amenazas y atentados. iA las armas!", en Las ruinas. Concepto, tratamiento y conservación, María del Valle Gómez de Terreros Guardiola y Luis Pérez-Prat Durbán (eds.), (Huelva: Universidad de Huelva, 2019), pp. 299- 242.

Porras 2018: Stephanie Porras, "Trading with the enemy: The Spanish market for Antwerp prints and paintings during the Revolt", en Netherlandish art and luxury goods in Renaissance Spain, Daan Van Heesch, Robrecht Janssen y Jan Van der Stock (eds.), (Nueva York: Harvey Miller Publisher, 2018), pp. 93-106.

Ruiz Gomar Campos 1985: José Rogelio Ruiz Gomar Campos, "El paso de Alonso Vázquez a Nueva España", en Andalucía y América en el Siglo XVII: actas de las III Jornadas de Andalucía y América, vol. 2, Bibiano Torres Ramírez y José J. Hernández Palomo (coord.), (La Rábida: Universidad de Santa María de la Rábida, 1985), págs. 163-170.

Salazar de Mendoza 1618: Pedro Salazar de Mendoza, El Glorioso Doctor San Ildefonso, Arçobispo de Toledo. Primado de las Españas, (Toledo: Diego Rodríguez impresor, 1618).

Sapori 2007: Giovanna Sapori, Fiamminghi nel cantiere Italia, 1560-1600, (Nápoles: Electa, 2007).

Schuckman y De Hood 1996: Christiaan Schuckman, (comp.) y D. De Hood Scheffer (ed.), Hollstein's Duch \& Flemis etchings, engravings and woodcuts 1450-1700, vol. XLIV-XLV, (Rotterdam: Sound\&Vision Interactive, 1996).

Serrera Contreras 1991: Juan Miguel Serrera Contreras, "Alonso Vázquez: el retablo mayor del Hospital de las Cinco Llagas", Archivo hispalense: Revista histórica, literaria y artística, 74, no 227, (1991), pp. 139-184.

Valdivieso 1992: Enrique Valdivieso, Historia de la pintura sevillana, (Sevilla: Guadalquivir S. L. 1992)

Valdivieso 2008: Enrique Valdivieso, Pedro de Campaña, (Sevilla: Fundación Endesa, 2008)

Enviado: 14/04/2019

Aceptado: 17/05/2019 